\title{
Anatomy: an old term, a new journal
}

\section{Dear Colleagues,}

We are very glad to present you the Volume 2, the first regular issue of our journal "Anatomy". As a new journal it received very positive international feedback in the ten months since the journal was launched. We must thank the authors and Editorial Board members for agreeing to give their valuable time to support a quality journal and their contributions in reviewing articles of this issue.

"Anatomy"; International Journal of Experimental and Clinical Anatomy, which is the official publication of Turkish Society of Anatomy and Clinical Anatomy (TSACA), with editorial contributions of international scientists who are leaders in their respective scientific areas, aims to convey peerreviewed high-level papers on all aspects of anatomy to international biomedical platform. It also aims to be a discussion platform among international anatomists about the recent education and research techniques. Thus, the scope of the journal is to make contributions relevant with the 21 st century to science and education as a serious resource.

Scientific journals that have begun publication in 19th and 20th century with focusing anatomy including histology and embryology together with physiology and pathology, has turned by time to general headlines on anatomy and morphology and towards the end of last century have continued their lifetime by going through subtitles with modern trends and gone on, on the basis of cell biology-histology on one hand and gross-clinical anatomy on the other hand. Additionally some of the older journals being published at national basis as can be understood from their names, have stepped forward towards globalization by changing their title as well as editorial board and become international.
The annual number of articles published in journals which are indexed in SCI under the category of Anatomy \& Morphology in 2007, was about 1000 . The number of such papers, which can be considered refined together with the ones published in related journals indexed regularly in Index Medicus/Medline database, is not above 2000 a year. When these data are compared with the number of researchers on the field of anatomy which can be expressed with ten thousands throughout the world and with the scientific congress contributions that increase everyday, it is clear that there is a case of insufficiency.

As founding editors of "Anatomy", our motivation to start a new international journal in a rooted science as anatomy was this necessity.

In accordance with the nature of peer-review system, the publication of the manuscripts and the results reaching to the readers are delayed. However, although the review processes relatively shortened with the development of electronic media, many researchers have difficulty in having their manuscripts, which give valuable results, to be published without a delay. A solution for this problem will be the increment in the number of journals relevant with the recent scientific norms at the international platform. Our journal "Anatomy" is ready to fill out its responsibilities by means of its aims, targeted and the policy of publication, determined.

Salih Murat Akkın, Hakan Hamdi Çelik

Editors-in-Chief 